\title{
IMPACT OF CLIMATIC VARIABILITY ON SHEEP HUSBANDRY PRACTICES AT LAMJUNG DISTRICT
}

\author{
S. Ghimire ${ }^{1}$ J. L. Yadav ${ }^{2}$, N. R. Devkota ${ }^{2 *}$ and S. Singh ${ }^{2}$ \\ ${ }^{1}$ National Cattle Research Program, Rampur, Chitwan \\ ${ }^{2}$ Agriculture and Forestry University, Rampur, Chitwan \\ (*email: nabadevkota.aafu@gmail.com)
}

\begin{abstract}
This study was done with 70 households of Uttarkanya and Bhujung VDC of Lamjung district to assess the impacts of climatic variability on sheep production and to document their adaptation practices to mitigate this variability. Household interview with structured-questionnaire were used to collect primary information, and secondary data was collected from District Livestock Service Office, Lamjung, Central Bureau of Statistics and Department of Hydrology and Meteorology. This study found that more than $80 \%$ of the farmer's perception about climatic parameters matched to those recorded by department of hydrology and meteorology. Similarly, the trend of sheep rearing in Lamjung district was found in decreasing whereas youths are least attracted to sheep farming, posing serious threat to the sustainability of sheep farming in the area. The study found that the climate change has affected sheep production and livelihood of farmers since many years. Analysis of climate data of Khudi region of Lamjung district showed increase in maximum temperature from $28.32^{\circ} \mathrm{C}$ to $28.63^{\circ} \mathrm{C}$ with an average change of $0.002^{\circ} \mathrm{C}$ per year and increase in minimum temperature from $15.03^{\circ} \mathrm{C}$ to $16.38^{\circ} \mathrm{C}$ with an average change of $0.015^{\circ} \mathrm{C}$ per year in past 20 years, resulting in hotter summer and warmer winter. Similarly, rainfall has shown decreasing trend associated with erratic patterns. Most important risk factor affecting sheep farming was increase in occurrence of different types of diseases due to climate change which was significantly different $(P<0.01)$. Farmers perceived decreased availability of grasses and pasture species in most cases in comparison to 10 years ago which was statistically significant $(P<0.01)$. Farmers have started adaptation measures that include shifting grazing zones to increase in access to pasture; preserve the forages and grasses for dry season; using regular vaccination and deworming against diseases and parasites; and constructed dipping tank to remove external parasites. These activities have helped sheep farming to adapt to climatic variability.
\end{abstract}

Key words: adaptation, climate change, Lamjung, sheep, survey

\section{INTRODUCTION}

Climate change is a global issue and Nepal is also facing problems related to climatic variability. For example, Nepal's temperature is rising faster than the global average, with a higher rate in the Himalayas (Shrestha et al., 1999). According to the definition of IPCC, "Climate Change is the change in climatic condition over time occurred either due to anthropogenic or nature induced causes, which remains for decades or even longer period showing distinct variation in its mean" (IPCC, 2007). Nepal's share in climate change is negligible. The population of Nepal is less than $0.4 \%$ of the world population and is responsible for only about $0.025 \%$ of annual greenhouse gasemissions (MOE, 2010).However, Nepal is highly vulnerable to climate change impacts. 
Nepal hosts different types of feedstuff in different agro-ecological zones, which are used to feed large number of animals and birds. Animal industry is suffering from many problems which are responsible to hinder the productivity and production level in Nepalese farming system. Among these, feed related problems are also equally responsible (Upreti \& Shrestha, 2006). Shortage of green forage in dry winter period is one of the pronounced problems in livestock sector (Upreti \& Shrestha, 2006), whereas the nutrition condition in the available feedstuff has not been given much attention which is equally important in livestock sector.

Livestock sector is an integral part of livelihood of Nepalese farmers. Most of the indigenous people living in higher altitude are highly dependent on migratory livestock system. Sheep, which has high importance in terms of wool and meat production in Nepal, are mainly being raised by indigenous people in mid and higher region in migratory system. In recent years Nepal has witnessed a deterioration of sheep production due to dwindling resources, an increase in disease prevalence and parasites, and changing climate is likely to accelerating the problems (Poudel et al., 2012). Vulnerability of the livestock sectors is high with climate variability (Thornton et al., 2007). Sheep population had declined by more than 6\% between 2001/02 to 2013/14 (MoAD, 2014). This study focuses on determining how the sheep health and nutrition in the forage are being affected by changing climate and what interventions are needed to increase the resiliency of the sheep to adapt to the changing climate and strengthen sheep production systems.

\section{MATERIALS AND METHODS}

The study was carried out at Uttarkanya and Bhujung Village Development Committees (VDCs) of Lamjung district of Nepal from April 2015 to October 2015. Both the Uttarkanya and Bhujung VDCs are nearer to each other so there is little variation in climatic pattern.

Thirty-five households from each VDC were selected by simple random sampling. Out of 634 households, only 70 households for the questionnaire survey were randomly selected for the study. $12.45 \%$ households of Uttarkanya and $9.91 \%$ households of Bhujung VDC were taken for the survey. Careful attention was paid to make the sample more inclusive (i.e. inclusion of farmers from different wealth categories, different ethnic groups and involvement in sheep farming etc). Inclusion criteria for the respondents for the questionnaire survey were that the respondent should be of age above 30 years and who have lived in the region for at least 10 years. The reason behind setting these inclusion criteria was because they could provide valuable and useful information regarding the effect of climate change in their region.

The primary data was collected through questionnaire survey, key informant interview, systematic field observation, structured and semi-structured interview with sheep keepers. To develop further idea of the study site, informal discussion and interview with key informant was done. Local leader, model farmers, teachers, social worker and other knowledgeable persons were taken as key informants. The interview was mainly focused on change in climatic parameters, impact on sheep production and possible adaptation measures. The data on weather parameters such as precipitation and temperature were collected from Khudi station of Lamjung district given by DHM, Nepal. Data on precipitation and temperature from 1994-2014 A. D. was analyzed and presented (Fig. 1, 2, $3,4,5)$. 
Data entry was done in Microsoft Excel 2010. For statistical analysis R ver. 3.2.5 (R Core Team, 2016) was used. Cross tabulation, Chi-square test and Fisher's exact test was performed in R using package "gmodels" (Warnes et al., 2015). Analysis of variance was calculated and Post hoc analysis for ANOVA was done by Tukey-Kramer method using PhStat2 ver 3.0.4. For meteorological data, 2d-line graph was created by Microsoft Excel 2010, and linear regression trend line was constructed, and equation was plotted on same graph.

\section{RESULTS}

\section{Perception on climate change by local people}

About Ninety percent of the respondents perceived that change in microclimate since last 10 years. The findings revealed that more than $87 \%$ of respondents experienced increased hotness compared to $2.85 \%$ respondents that they did not feel so. Increased climate extremes (e.g. warm and cold temperature) were experienced by more than $90 \%$ of the respondents. Similarly, decrease in water resources was experienced by more than $85 \%$ of the respondents whereas very few respondents also felt about increase in water resources by $5.70 \%$ of the respondents and $7.15 \%$ of the respondents experienced not difference in water resources in comparison to last 10 years. Similarly, $88.57 \%$ of the respondent's experienced increased occurrence of drought compared to less than 5\% respondents perceived that they did not experiencing increasing occurrence of drought (Table1). Similarly, greater than $91 \%$ of the respondents experienced that there was irregular in the time of monsoon whereas more than $84 \%$ of respondents perceived that delayed starting of monsoon and only less than $10 \%$ of the respondents felt earlier starting of monsoon and no difference in the time of monsoon comparison to since last 10 (Table2).

Table 1: Change in microclimate as perceived by the respondent ( $\%$ response) since last 10 years

\begin{tabular}{llll}
\hline Responses & Increased (\%) & Decreased (\%) & No difference (\%) \\
\hline Hotness & 87.15 & 2.85 & 10.00 \\
Climate extremes & 91.43 & 1.42 & 7.15 \\
Water resources & 5.70 & 87.15 & 7.15 \\
Occurrence of drought & 88.57 & 2.86 & 8.57 \\
\hline
\end{tabular}

Table 2: Change in time of onset of monsoon perceived by the respondent (\% response) since last 10 years

\begin{tabular}{ll}
\hline Onset of time of monsoon & Response (\%) \\
\hline Early monsoon & 7.15 \\
Delayed monsoon & 84.30 \\
Irregular monsoon & 91.45 \\
No difference & 8.55 \\
\hline
\end{tabular}

\section{Trend of climatic variables on Lamjung district}

From the climatic data it was seen that the July and August were the wettest months and the November and December were the driest months (Figs. 1, 2, 3, 4). The trend line indicates that the maximum temperature (Tmax) is increasing compared to past, from regression equation we can say 
that Tmax is increasing at the rate of $0.002^{\circ} \mathrm{C}$ per year. Likewise, minimum temperature (Tmin) is increasing at the rate of $0.015^{0} \mathrm{Cper}$ year.

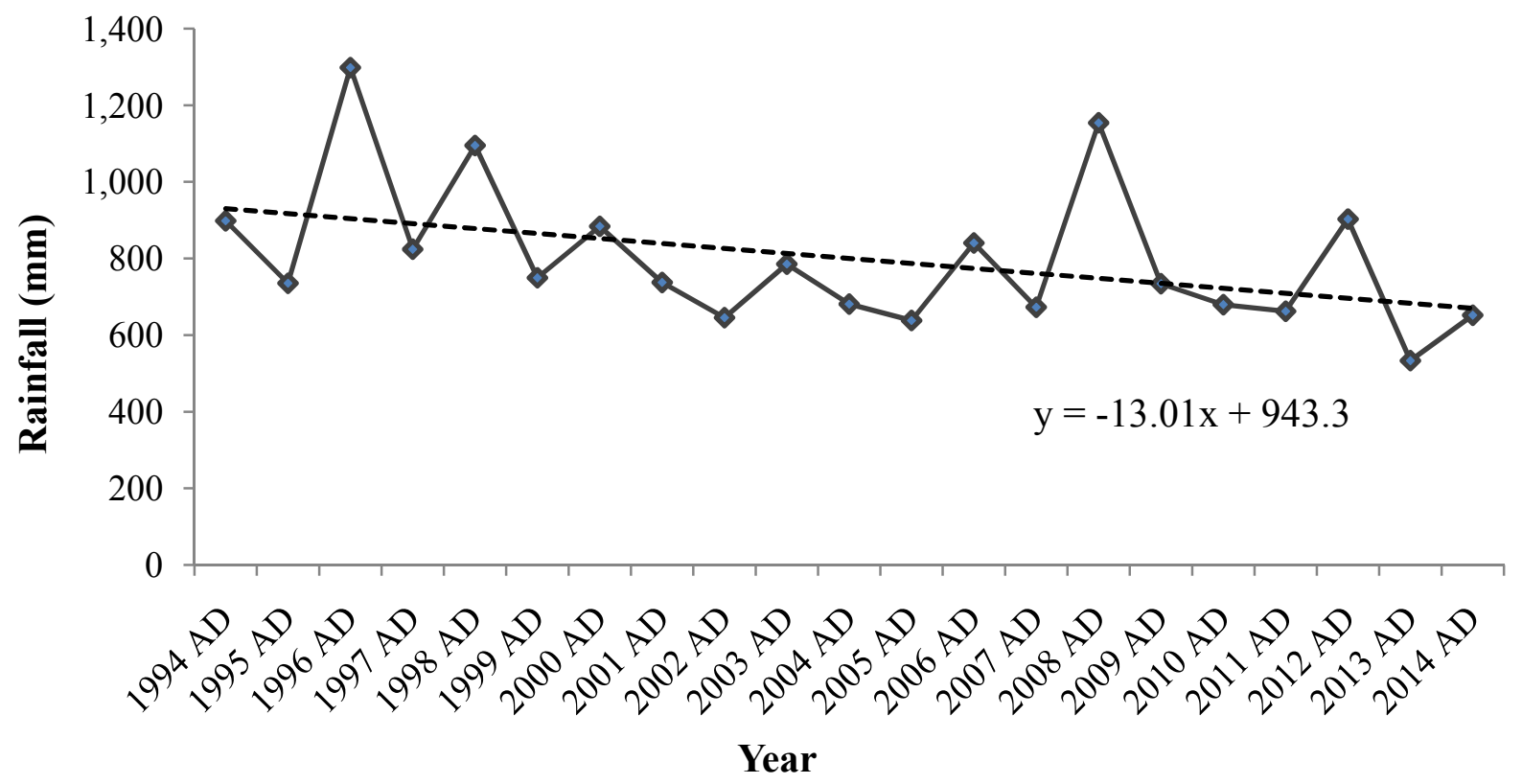

Fig. 1: Rainfall (mm) during July from 1994 to 2014 AD. Dotted line shows the trend line

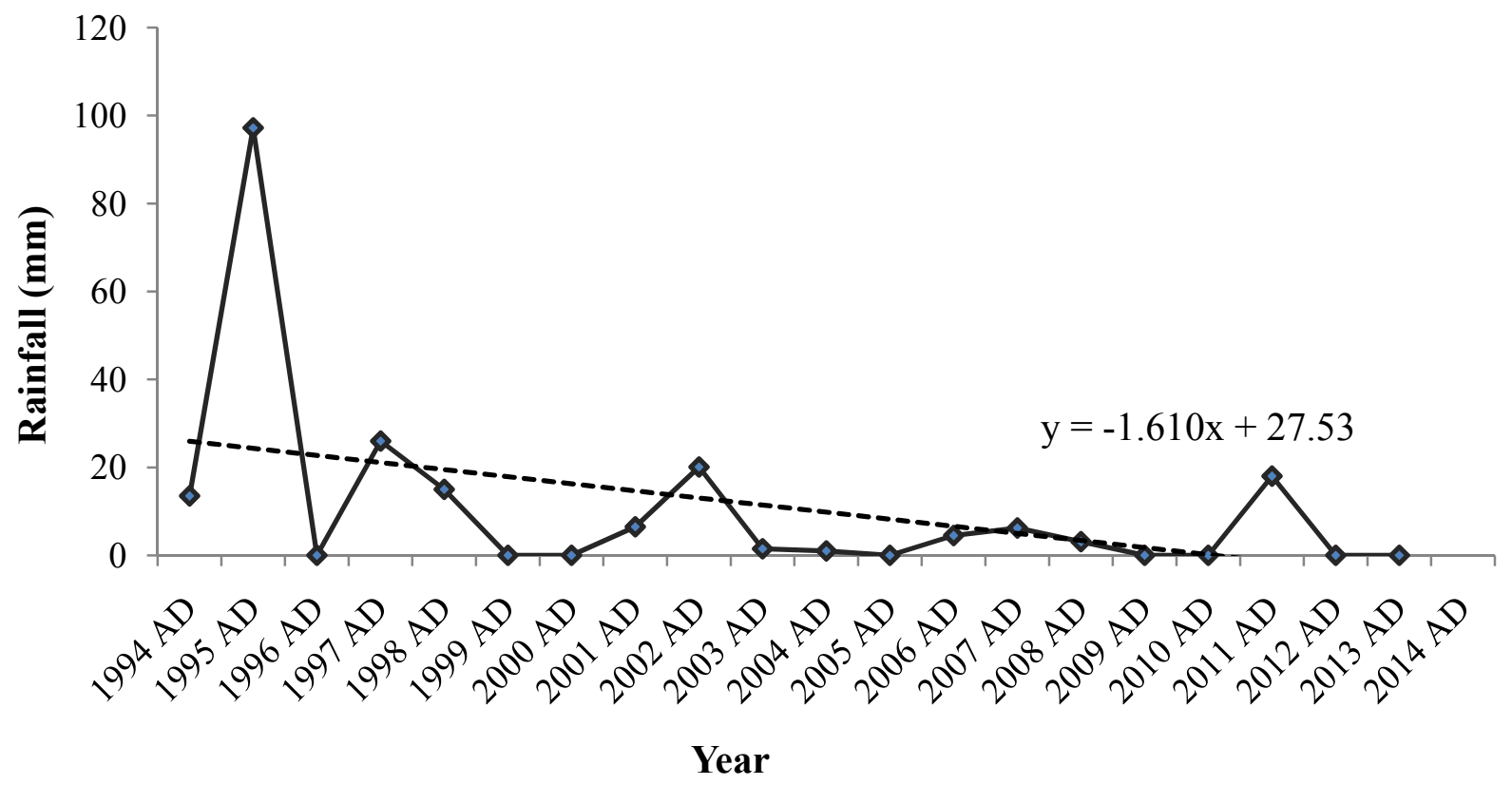

Fig. 2: Rainfall (mm) during August from 1994 to 2014 AD. Dotted line shows the trend line 


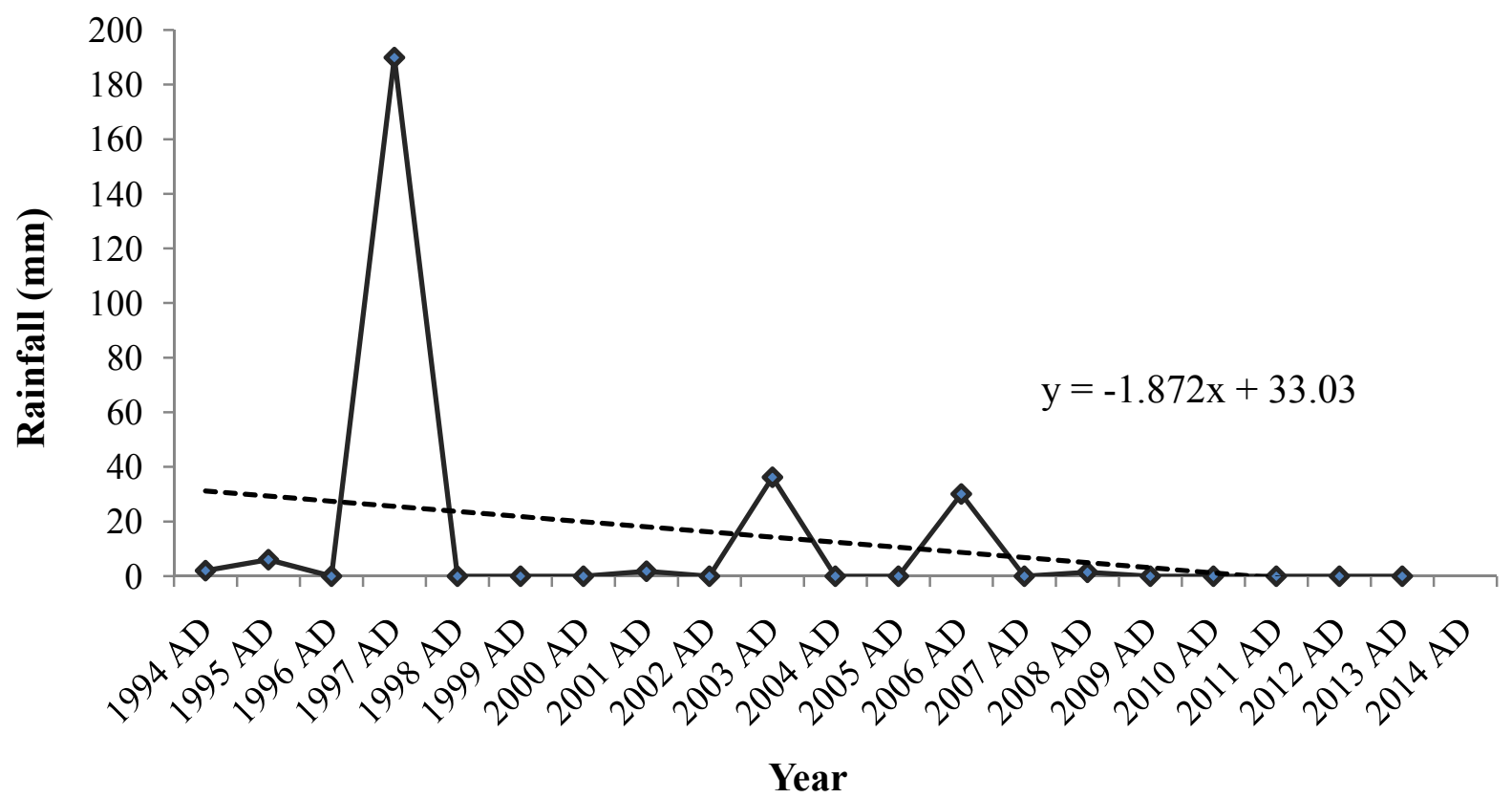

Fig. 3: Rainfall (mm) during November from 1994 to 2014 AD. Dotted line shows the trend line

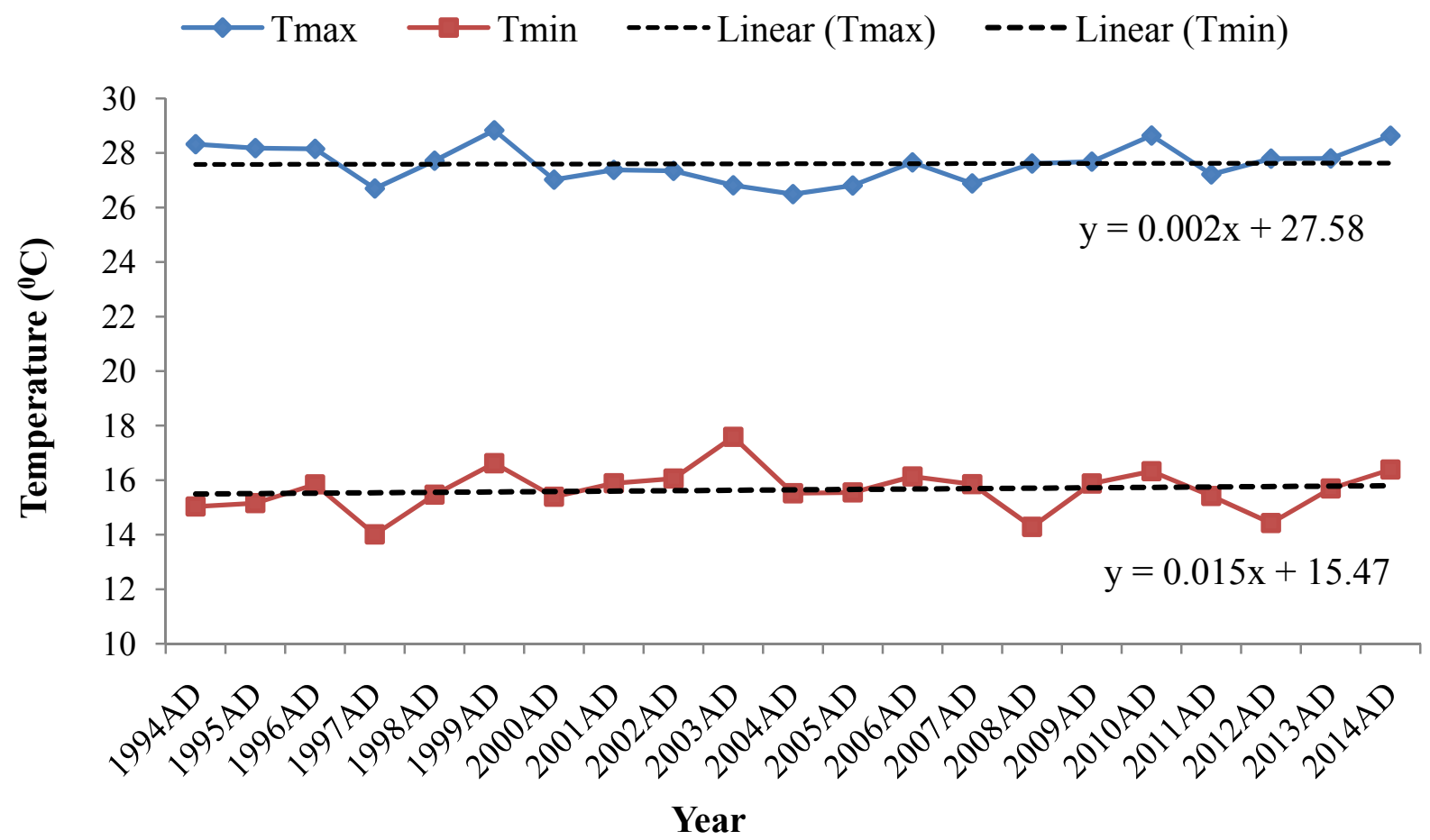

Fig. 4: Temperature pattern of Khudi region 


\section{Factors affecting sheep farming}

Based on farmers perception climate change and others factors such as labor scarcity, poor livestock service, poor availabilty of public land, poor availability of pastures due to community forest was statistically similar in both the VDCs of Lamjung district. It was found that more than $40 \%$ of the respondents in Bhujung VDC and about 30\% of Uttarkanya VDC perceived that sheep farming is affected by climate change. Similarly, about $30 \%$ of the respondents in Bhujung VDC and $40 \%$ respondents in uttarkanya VDC felt that sheep farming was affected by labor scarcity. Likewise, about $30 \%$ of the respondents in Uttarkanya VDC perceived that poor livestock service could be one of the factor affecting sheep farming whereas only about $10 \%$ of the respondents in Bhujung VDC realized that poor livestock service. Poor availability of pastures due to community forest was found as one of the important factors afeecting sheep production recorded by the $34.29 \%$ and $28.57 \%$ in Uttarkanya and Bhujung VDC respectively. However, lower percentage of the respondents in both Bujung and Uttarkanya VDC $5.71 \%$ and $8.57 \%$ respectively perceived that poor availability of public land was a factor affecting sheep farming. (Table3). However, Chisquare test indicates that there was no significant difference in the response on the factors affecting sheep farming.

Table 3: Percent responses factors affecting sheep farming at Bhujung and Uttarkanya VDCs

\begin{tabular}{lllll}
\hline Factors affecting sheep farming & Bhujung & Uttarkanya & Probability & $\chi$ 2-value \\
\hline Climate change & 42.86 & 29.41 & NS & 1.349 \\
Labor scarcity & 28.57 & 38.24 & NS & 0.725 \\
Poor livestock service & 11.43 & 28.57 & NS & 3.214 \\
Poor availability of public land & 5.71 & 8.57 & NS & FET \\
$\begin{array}{l}\text { Poor availability of pastures due to } \\
\text { community forest }\end{array}$ & 28.57 & 34.29 & NS & 0.265 \\
\hline * and ** = significance levels at $\mathrm{P}<0.05$ and $\mathrm{P}<0.01$ respectively, NS= not significant. FET: Fisher's Exact Test
\end{tabular}

\section{Major risk factor in sheep farming}

Most important risk factor affecting sheep farming was increase in occurrence of different types of diseases due to climate change which was significantly different $(\mathrm{P}<0.01)$ as compared to other risk factors. Thereafter, lack of labors, water scarcity due to drought and decrease in pasture land were second important risk factors, there was no significant difference $(\mathrm{P}>0.05)$ among these risk factors. Lack of market was third important risk factor. Decrease in agriculture production due to climate change was found as significantly lesser risk factor for sheep farming as compared to other risk factors (Table 4).

Table 4: Mean risk for various risk factors in sheep farming

\begin{tabular}{|c|c|c|c|c|}
\hline Risk factors & Mean & SEM & Probability & F-value \\
\hline 1. Occurrence of disease due to $\mathrm{CC}$ & $4.04^{\mathrm{a}}$ & 0.16 & $* *$ & 44.698 \\
\hline 2.Decrease in agriculture production due to $\mathrm{CC}$ & $0.78^{\mathrm{d}}$ & 0.15 & & \\
\hline 3. Decreased in pasture land due to community forest & $2.65^{b}$ & 0.19 & & \\
\hline 4.Lack of market & $1.70^{\mathrm{c}}$ & 0.16 & & \\
\hline 5.Water scarcity due to drought & $2.79^{b}$ & 0.17 & & \\
\hline 6.Lack of labors & $3.00^{\mathrm{b}}$ & 0.19 & & \\
\hline
\end{tabular}




\section{Adoption of new methods to minimize effects of climate change}

Preserve forage and grasses for dry season, make shed to protect the animals from heat, cold, and windstorm, regular vaccination, deworming, consulting with technician, provide nutritious diet in cold season are the measures adapted by the farmers. Percent responses on adoption of new methods to minimize effects of climate change at Bhujung and Uttarkanya VDCs was shown in table 5. Most respondents (77.14\% in Bhujung and $82.86 \%$ in Uttarkanyana VDC) have adopted new methods to minimize effects of climate change. The statistical test indicates that there was no significant difference in the adoption of new technology in two different VDCs.

Table 5: Percent responses on adoption of new methods to minimize effects of climate change at Bhujung and Uttarkanya VDCs

\begin{tabular}{lllll}
\hline Adoption of new methods & Bhujung & Uttarkanya & Probability & $\boldsymbol{\chi 2}$-value \\
\hline Don't know & 14.29 & 14.29 & NS & FET \\
No & 8.57 & 2.86 & & \\
Yes & 77.14 & 82.86 & & \\
\hline * and ** = significance levels at $\mathrm{P}<0.05$ and $\mathrm{P}<0.01$ respectively, $\mathrm{NS}=$ not significant. & FET: Fisher's Exact Test.
\end{tabular}

\section{DISCUSSION}

\section{Perception on climate change by local people}

Statistical analysis of climatic parameters has shown changing scenario of Lamjung District. Most of the residents especially elder people think that trend of temperature and rainfall has changed from the last 10 years. Increasing trend of temperature rise and precipitation extremes have been observed in Nepal along with the incidences of heavy precipitation at many places (Baidya et al., 2008). Manandhar (2009) reported a gradual increase in temperature in different ecological zones of the western development region of Nepal.

\section{Major risk factor in sheep farming}

Most important risk factor affecting sheep farming was increase in occurrence of different types of diseases due to climate change which was significantly different $(\mathrm{P}<0.01)$ compared to other risk factors. Due to the availability of the pastureland sheep and goat rearing is the main source of income generation in this region. According to key informants' interview with chief of DLSO, major disease and parasitic infestation of sheep population in this region are diarrhea, PPR, tympani, flea, lice, leeches, and different skin infestation has been increased in recent years.

Both the sites of respondent perceived the prevalence of the internal parasite and external parasite is high as compared to the last 10 years. Most common types of disease include the skin infections caused by the external parasites. It may be due to the presence of suitable environment for the parasite to grow, develop and adapt with the changing climatic pattern.

New parasites and diseases in all altitude especially skin diseases in livestock have been reported to be emerging due to climate change (Thakur, 2011). As suggested by Thoranton et.al, (2007) that vector borne disease could be affected by the expansion of vector population into cooler areas and change in pattern during wetter years, which could also lead to expanding vector population and large-scale outbreak of disease. Helminth infections are greatly influenced by change in temperature. 


\section{Adoption of new methods to minimize effects of climate change}

Most of the respondents (77.14\% in Bhujung and $82.86 \%$ in Uttarkanya) have adopted new methods to minimize effects of climate change. And, the response was not significantly different $(\mathrm{P}>0.05)$ in both places. Both the sites are nearer to each other and their socioeconomic and demographic characters are like each other. Sheep farmers have traditionally adapted to various environmental and climatic changes by building on their in-depth knowledge of the environment in which they live. Transhumance system is generally practiced by sheep herders is one of the successful examples of seasonal adaptive mechanism. Introducing mixed livestock farming system such as stall fed system and pasture grazing, modifying stock routing and distances to adjust with the changed environment, cultivation of drought tolerant varieties of fodder and forage, creation of awareness among the farmers about climate change, improve the capacity of sheep herders by providing training, make shed to protect the animals from heat, cold, windstorm etc., preserve the forage and grass for dry season in some extent, regular vaccination, deworming, consulting with technician, provide nutritious diet in cold season, deep boring for ground water and rain water harvesting against erratic rainfall/drought are the some management strategies have been adopted by the farmers.

\section{CONCLUSION}

The vulnerability of sheep farming to climate change is an important concern in the study sites of Lamjung District where many rural households, small and marginal farmers depend on sheep production. Findings revealed that a significant number of respondents in the survey sites perceived an increase in temperatures together with a decline in rainfall affecting sheep productivity and overall status of sheep production. Because of change in temperature and rainfall pattern, there has been increased in infectious diseases and parasitic infestation; along with decrease availability of feeds and pasture is affecting the productivity of sheep. Decreased productivity and food insufficiency have forced the farmers to adopt other occupations. Farmers have been using their indigenous knowledge and experiences in implementing adaptation measures against climatic variability at local level. They have adopted adjustments in livestock management practices and some external technologies to cope with the impacts of climatic variability. The autonomous, short term adjustments in livestock help them to cope to some extent but if changes progress in the same manner and appropriate adaptation strategies are not developed, the sheep farmers will be at greater risk in the future.

\section{ACKNOWLEDGMENT}

The author thankful to all the respondents of Uttarkanya and Bhujung VDCs of Lamjung district for their valuable time and genuine information with great hospitality without whose cooperation this study would not have been succeeded. Author is also thankful to Local Initiatives for Biodiversity, Research and Development (LI-BIRD) for the financial support to this study.

\section{REFERENCES}

Baidya, S.K., Shrestha, M.L. and Sheikh, M.M. (2008). Trends in daily climatic extremes of temperature and precipitation in Nepal. Journal of Hydrology and Meteorology, 5(1): 38-53. 
Shrestha, A.B., Wake, C.P., Mayewski, P A. and Dibb, J. E. (199). Maximum temperature trends in the Himalaya and its vicinity: An analysis based on temperature records from Nepal for the period 1971-1994. Journal of climate12: 2775-2787.

IPCC. (2007). Intergovernmental panel on climate change. Climate change 2007. Synthesis report.

Manandhar, S. (2009). Perception and adaptation to climate change by farmers in different ecological zones of the western development region of Nepal. Thesis, M.Sc. Asian Institute of Technology (AIT), School of Environment Resources and Development, Thailand.

MoAD. (2014). Statistical information on Nepalese Agriculture. Government of Nepal. Ministry of Agricultural Development, Kathmandu, Nepal.

MOE. (2010). National adaptation programme of action draft. Ministry of Environment, Government of Nepal.

Poudel, D.D., Thakur, R.P., Singh, A., Tiwari, M.R. and Deramus, A. (2012). Capacity building and strengthening of livestock production systems while adapting to climate change in Nepal.

Thakur, R.P. (2011). Climate change: livestock health and production in Nepal. Proceeding of Climate change: livestock sector, change and livestock-research opportunities and challenges for poverty alleviationvulnerability and adaptation in Nepal.

Thornton, P., Herrero, M., Freeman, A., Mwai, O., Rege, E., Jones, P. and McDermott, J. (2007). Vulnerability, climate. SAT eJournal | ejournal. icrisat. org, 4(1): 1-23.

Upreti, C.R. and Shrestha, B.K. (2006). Nutrient contents of feeds and fodder in Nepal. Nepal Agriculture Research Council (NARC). Animal Nutrition Division, Kathmandu, Nepal. 